\title{
The Prophylactic Role of Lipopolysaccharide of Pseudomonas aeruginosa Against Corneal Infection
}

Pseudomonas aeruginosa الدور الوقائي لمتعدد السكريد الثحمي

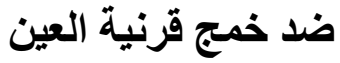

May T. Flayyih

Rasmyia A. Abu-risha Jinan M. Hasan

جنان محمد حسن College of Science/ University of Baghdad
رسمية عبا ابو ريشة
كلية العلوم / جامعة بغداد الئه
مي طالب فليح

\section{Abstract}

Q he lipopolysaccharide (LPS) was extracted by using digestive enzyme and hot phenol water method from Pseudomonas aeruginosa $P$ (10) a local isolate from patient suffering from eye infection-and partially purified by gel-filtration chromatography. The sera were prepared in rabbits, they were injected with five doses over 70 days of different concentrations of partially purified LPS. The pathological infection was done by using two groups of female mice; the first group represents the non-immunized group while the second group represents the immunized group. The left and right eyes of the two groups were scratched then the left eyes were infected with $P$. aeruginosa $P$ (10) while the right eyes serve as a control scratched eye. In the second group that represents the immunized group, the mice were immunized intraperitoneally (i.p.) with sera after and before scratching and infection with $P$. aeruginosa. The results have shown that the typical pathological scores were observed in the left eyes of nonimmunized mice group $72 \mathrm{hr}$. after infection with $P$. aeruginosa while no pathological scores were observed in the left eyes of immunized mice. This indicated that the immunization with LPS gave a protection against P.aeruginosa corneal infection. These results indicate that immunization with LPS reduces the corneal infection caused by $\boldsymbol{P}$. aeruginosa.

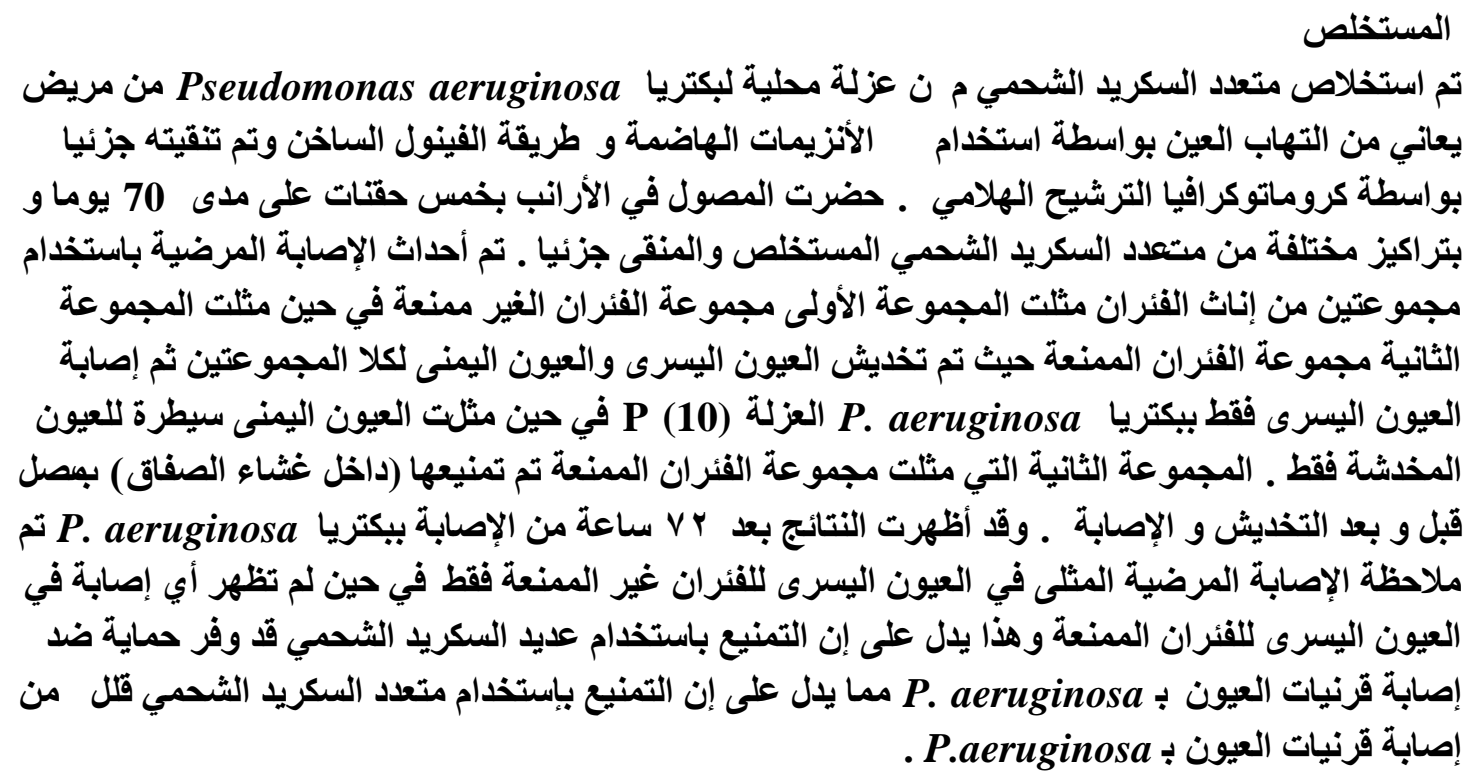




\section{Introduction}

Pseudomonas aeruginosa is the most commonly encountered gram-negative species that is not a member of the family Enterobacteriaceae [1]. It is widely distributed in nature and it is commonly present in moist environment in hospitals. It can cause disease in humans with abnormal host defenses and colonize normal humans in whom it is saprophyte [2].

The virulence factors of $P$. aeroginosa include: exotoxins, endotoxins, and a variety of cytotoxic substances including proteases, phospholipases, rhamnolipids and the blue-green pigment pyocyanin, and alginate-like exopolysaccharide that is responsible for the mucoid phenotype [3], in addition to pili and intrinsic resistance to many antimicrobial agent [1]. Lipopolysaccharide (LPS) is the major component of the outer membrane of gram-negative bacteria; it protects the pathogenic bactera from host defenses and mediates the entry of the bacteria into eukaryotic cells [4]. Keratitis caused by $P$. aeroginosa is one of the most rapidly developing and destructive diseases of the cornea. Once the bacteria infect the cornea, complex host tissue reactions occur, including inflammation, cellular and humoral immune responses and degradation of stromal proteins [5]. It is very uncommon in a normal eye and usually only develops when the ocular defense has been compromised [6]. P. aeroginosa keratitis following trauma to the cornea may result in blindness [7]. During corneal infection LPS has been proposed to be a ligand responsible for the invasion of the cornea [8]. This study aims to:

isolate $P$. aeruginosa from patients suffering from corneal infection, extracting and partially purifying lipopolysaccharide and studying the prophylactic role of LPS of $P$. aeruginosa by preparing antiserum against LPS in rabbits and by active immunization in mice.

\section{Methods}

\section{Bacterial Isolates}

Specimen were collected by cotton swap. The collected specimen were inoculated on MacConkey agar and Cetrimide $0.03 \%$ medium then incubated at $37^{\circ} \mathrm{C}$ for $24 \mathrm{hr}$. The isolated colonies were identified by biochemical tests [1] and the identification was confirmed by API $20 \mathrm{E}$ system and agglutination sera test for the grouping of $P$. aeruginosa (Sanofi Diagnostic Pasteur).

\section{Extraction and Partial Purification of LPS of Pseudomonas aeruginosa}

According to [9] the LPS was extracted and partially purified. LPS was extracted by using digestive enzymes and hot water phenol method and the purification by gelfiltration chromatography by using Sephacryl 200S (unpublished study). Protein was determined according to [10], carbohydrates were determined according to [11] and the nucleic acids were determined according to [12].

\section{Preparation of antisera}

Antisera were prepared in rabbits. Two rabbits (2-2.5) kg were hyperimmunized over a period of 70 days by five injections, the first two injections were given intramuscularly with olive oil as an adjuvant, on day 0 , one $\mathrm{ml}$ of $10 \mu \mathrm{g}$ of LPS in olive oil and on day 14, one ml of $20 \mu \mathrm{g}$ of LPS in olive oil, the third, fourth and fifth injections were given intravenously on days $28,40,56$ respectively, one $\mathrm{ml}$ of $50 \mu \mathrm{g}$ 
of LPS. One control rabbit was injected PBS instead of LPS. On day 70, blood was collected from immunized and control rabbits by heart stabbing and the sera was pooled [13]. Indirect passive hemagglutination was used according to [14] in order to measure antibodies titers against LPS antigens of Pseudomonas aeruginosa in immunized and control rabbits sera.

\section{Corneal infection experiment}

Two groups of mice were used, each group consisting of 4 female mice. The first group which was not injected with sera represents a non- immunized group. The second group was injected intraperitoneally (i.p) with $0.2 \mathrm{ml}$ of $2 \times$ concentrated rabbit serum [11] $18 \mathrm{hr}$ prior to corneal challenge and again $2 \mathrm{hr}$ after corneal challenge. This group represents the immunized group [15]. Corneal infection was initiated on scratch-injured eyes of mice as described by [16]. Briefly, mice eyes of the two groups were wounded by gently scratching the corneal surface with a sterile 26-gauge needle. $5 \mu \mathrm{l}$ of bacterial cell suspension $1 \times 10^{8}$ cell $/ \mathrm{ml}$ viable organisms were delivered onto incise left corneas with a micropipette having a sterile disposable tip, whereas the right cornea of each mouse was served as a control scratching eye. Control mouse for each group has normal eyes without immunization or scratching. Generally, maximal pathology scores were observed 72h after infection [15].

\section{Results and Discussion}

-Studying the Prophylactic Role of LPS of P. aeruginosa by Corneal Eyes Infection of Non-immunized and immunized mice

The clinical examination show that there were no pathological scores were observed in the left or right eyes of control mice that have not been immunized, scratched or infected with $P$. aeruginosa as shown in Figures (1 A, 1 B).

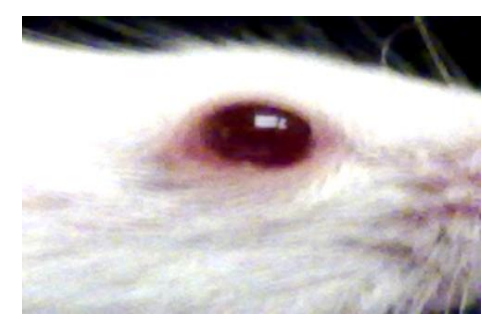

Figure (1 A): Photograph of the left eve of control mouse

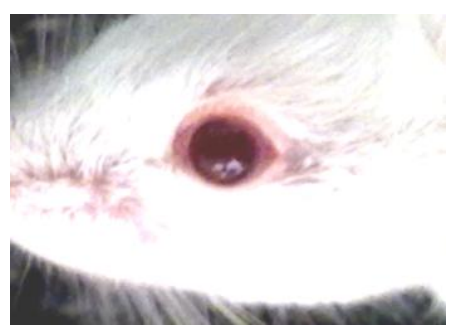

Figure (1 B): Photograph of the right eve of control mouse

Maximal pathological scores were only observed in the left eyes of non-immunized mice that were scratched by 26 gauge sterile needles and challenged with $5 \mu 1$ of $1 \times 10^{8}$ cell/ml viable organism of $P$. aeruginosa $\mathrm{P}(10)$ isolate, $72 \mathrm{hr}$. after infection, as shown in Figure (2 A).

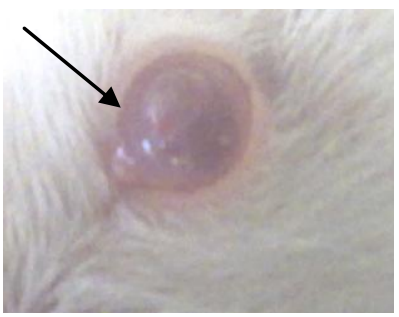

Figure ( $2 \mathrm{~A})$ : Photograph of the left eye of non-immunized mouse that was scratched by and challenged with Pseudomonas aeruginosa P (10) showing the pathological score $(\rightarrow)$ 
While no scores were observed in the right eye of the same mice that was only scratched but not infected, as shown in Figure (2 B).

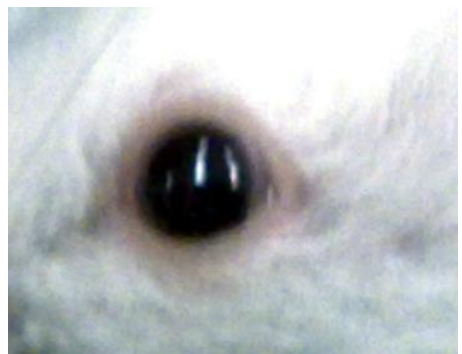

Figure (2 B): Photograph of the right eye of non-immunized mice that was only scratched and not infected by $P$. aeruginosa. No pathological score was observed

No scores were observed either in the left eyes of the immunized mice that were immunized (i.p) with $0.2 \mathrm{ml}$ of $2 \mathrm{x}$ of concentrated rabbit anti LPS sera, 18hr. before and 1-2 hr. after infection with $P$. aeruginosa, as shown in Figure (3 A) or in the right eyes that were scratched only but not infected with $P$. aeruginosa, as shown in figure (3 B).

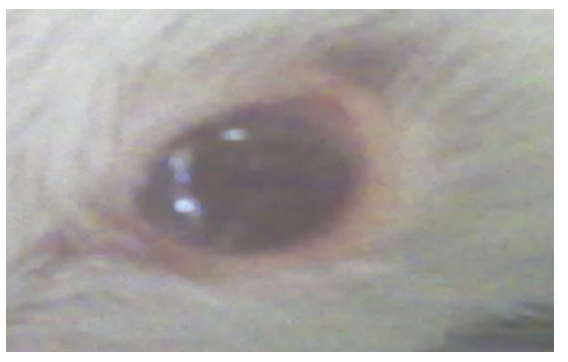

Figure (3 A): Photograph of the left eye of immunized mouse that was immunized and infected by Pseudomonas aeruginosa P (10). No pathological score was observed

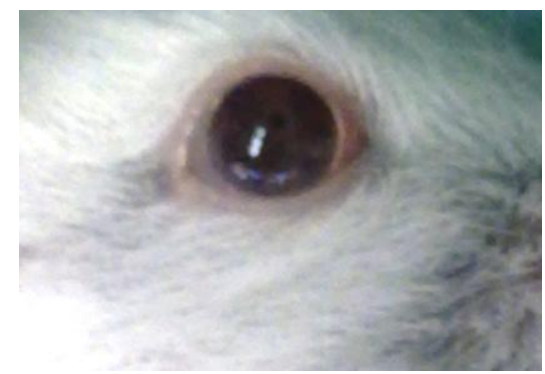

Figure (3 B): Photograph of the right eye of immunized mouse that was immunizedand not infected by Pseudomonas aeruginosa $\mathbf{P}(10)$. No pathological score was observed

These results show that immunization with LPS against $P$. aeruginosa corneal infection gave a protection against $P$. aeruginosa corneal infections and reduced the infection, as shown in figure ( $3 \mathrm{~A})$ that demonstrated that no pathological scores were observed in the left eyes of immunized mice while the pathological scores were clearly observed in the left eye of non-immunized mice Figure $(2 \mathrm{~A})$. The clinical examination of non-immunized animals challenged with $P$. aeruginosa developed a predominantly edematous response at $24 \mathrm{~h}$ post-challeng [16], while [15] recorded that the maximal pathology scores were observed $72 \mathrm{~h}$ after infection. LPS isolated from several strains of $P$. aeruginosa was derived either from the phenol or water phase was found to be highly immunogenic and protective in mice [17].

$P$. aeruginosa-induced keratitis is a sight-threatening disease, it is in large part a consequence of the inflammatory response invoked by the host [18]. The pathogenesis of $P$. aeruginosa keratitis is a maltifactorial process requiring a combination of different bacterial and host cell factors [19]. Both bacterial (e.g., LPS) and host factors released from infiltrating cells during infection are thought to contribute to a rapidly progressing liquefactive stromal necrosis [20]. The administrating LPS- 
specific antibodies, either prophylactically or therapeutically may be of a value in the treatment of $P$. aeruginosa corneal infections; this inconforming with the result recorded in this study [21].

\section{References}

1. Forbes, B. A.; Sahm, D. F. and Weissfeld, A. S. (2007). Bailey and Scotts Diagnostic Microbiology. $12^{\text {th }}$ ed. Mosby, Inc. China. pp. 340-350.

2. Brooks, G. F.; Butel, J. S.; Carroll, K. C. and Morse, S. A. (2007). Jawetz, Melnick and Adelbergs Medical Microbiology. $24^{\text {th }}$ ed. The McGraw-Hill Companies, Inc. USA.

3. Govan, J. R. W. (2005). Pseudomonas and non-fermenters. In: Medical Microbiology. $16^{\text {th }}$ ed. (Greenwood, D.; Slack, R. C. B. and Peutherer, J. F. (eds)). Churchill Livingstone. China. pp. 282-287.

4. Brandenburg, K. and Wiese, A. (2004). Endotoxins: Relationships between structure, function and activity. Curr. Top. Med. Chem. 4(11): 1127-1146.

5. Hazlett, L. D.; McClellan, S.; Kwon, B. and Barrett, R. (2000). Increased severity of Pseudomonas aeruginosa corneal infection in strains of mice designated as Th1 versus Th2 responsive. IOVS. 41(3): 805-810.

6. Kanski, J. J. (2007). Clinical Ophthalmology.

7. Gerke, J. R. and Nelson, J. L. (1977). Oral $6^{\text {th }}$ ed. Elsevier Limited. China. pp. 250260. vaccination and multivalent vaccine against

8. Van Delden, C. (2004). Virulance factors in Pseudomonas aeruginosa keratitis. IOVS. 16(1): 76-80.Pseudomonas aeruginosa. In: Pseudomonas: Virulance and Gene Regulation. Vol.2. (Ramos, J. L. (ed)). Plenum Publishers, New York. PP. 3-46.

9. Johnson, K. G. and Perry, M. B. (1975). Improved techniques for the preparation of bacterial lipopolysaccarides. CAN. J. Microbiol. 22: 29-34.

10. Lowry, O. H.; Rosebrough, N. J.; Farr, A. L. and Randall, R. J. (1951). Protein measurment with folin phenol reagent. J. Biol. Chem. 193(1): 265-275.

11. Dubois, M.; Gilles, K. A.; Hamilton, J. K.; Rebers, P. A. and Smith, F. (1956). Colorimetric methods for determination of sugars and related substances. Anal. Chem. 28(3): 350-356.

12. Ashwell, G. (1957). Colorimetric analysis of sugar. In: Methods in Enzymology.Vol.3. (Colowick, S. P. and Kaplan, N. O. (eds)). Academic press Inc. Publishers, New York. PP.: 73-105.

13. Cryz, S. J.; Fürer, E. and Germanier, R. (1983). Passive Protection against Pseudomonas aeruginosa infection in an experimental leukopenic mouse model. Infect. Immun. 40(2): 659-664.

14. Herbert, W. J. (1978). Passive haemagglutination with special reference to the tanned cell technique. In: Handbook of Experimental Immunology. Vol.1. 3 rd ed. (Weir, D. M. (ed)). Blackwell Scientific Publications, Great Britain. pp. 20.1 - 20.19.

15. Zaidi, T. S.; Priebe, G. P. and pier, G. B. (2006). A live-attenuated Pseudomonas aeruginosa vaccine elicits outer membrane protein-specific active and passive protection against corneal infection. Infect. Immun. 74(2): 975-983. 
16. Thakur, A.; Kyd, J.; Xue, M.; Willcox, M. D. P. and Cripps, A. (2001). Effector mechanisms of protection against Pseudomonas aeruginosa keratitis in immunized rats. Infect. Immun. 69(5): 3295-3304.

17. Cryz, S. J.; JR; Pitt, T. L.; Fürer, E. and Germonier, R. (1984). Protection against fatal Pseudomonas aeruginosa burn wound sepsis by immunization with lipopolysaccharide and high-molecular-weight polysaccharide. Infect. Immun. 43(3): 795-799.

18. Hazlett, L. D. (2004). Corneal response to Pseudomonas aeruginosa infection.Prog. Retin. Eye Res. 23: 1-30.

19. Lee, E. J.; Cowell, B. A.; Evans, D. J. and Fleiszig, S. M. (2003). Contribution of ExsA-regulated factors to corneal infection by cytotoxin and invasive Pseudomonas aeruginosa in a murine scarification model. IOVS. 44(9): 3892-3898.

20. Pillar, C. M., and Hobden, J. A. (2002). Pseudomonas aeruginosa exotoxin A and keratitis in mice. IOVS. 43: 1437-1444.

21. Preston, M. J.; Gerceker, A. A.; Koles, N. L.; Pollack, M. and Pier, G. B. (1997). Prophylactic and therapeutic efficacy of immunoglobulin $G$ antibodies to Pseudomonas aeruginosa lipopolysaccharide against murine experimental corneal infection. IOVS. 38(7): 1418-1425. 